\title{
Bilateral retinal vasculitis in a patient with lichen planus
}

\section{Vasculite retiniana bilateral em um paciente com líquen plano}

\author{
Seyhan Dikcl ${ }^{1}$, OĞuzhan Genç ${ }^{1}$, Turgut Yilmaz ${ }^{1}$, Penpe Gül Firat ${ }^{1}$
}

\begin{abstract}
Lichen planus (LP) is an autoimmune, inflammatory disease of unknown etiology that commonly affects the skin and mucous membranes. Retinal vasculitis is a group of vision-threatening disorders, in which autoimmunity is thought to play a role in pathogenesis. We present the case of a patient who was diagnosed with retinal vasculitis and who was followed up for mucosal LP. LP has not been reported as a cause of retinal vasculitis in the literature. We believe that the retinal vasculitis in this case was related to LP because cellular immunity plays a role in the pathogenesis of both entities.
\end{abstract}

Keywords: Retina; Retinal vasculitis; Lichen planus; Fluorescein angiography

\section{RESUMO}

Líquen plano (LP) éuma doença auto-imune, inflamatória de etiologia desconhecida que normalmente afeta a pele e membranas mucosas. Vasculite retiniana engloba um grupo de doenças que ameaçam a visão em que a autoimunidade parece desempenhar um papel na sua patogênese. Apresentamos um caso que foi diagnosticado com vasculite da retina e que tinha sido acompanhado com $L P$ de mucosa. $L P$ não consta entre as causas de vasculite retiniana na literatura. Acreditamos que a vasculite da retina no nosso caso, foi relacionado com o LP considerando que a imunidade celular desempenha um papel na patogênese de ambas as entidades.

Descritores: Retina; Vasculite retiniana; Líquen plano; Angiofluoresceinografia

\section{INTRODUCTION}

Lichen planus (LP) is an autoimmune, inflammatory disease of unknown etiology that commonly affects the skin, nails, hair, and mucous membranes in middle-aged adults( ${ }^{(1)}$. Retinal vasculitis comprises a group of disorders characterized by retinal vascular inflammation accompanied by intraocular inflammation, and autoimmunity is thought to play a role in its pathogenesis. Diagnosis is made with ophthalmoscopy and fundus fluorescein angiography (FA) in cases of retinal vasculitis that threaten vision. Retinal vascular sheathing, vitritis, and accompanying cystoid macular edema are among the typical clinical findings, and staining and leakage of the retinal vessels on FA are characteristic in active disease ${ }^{(2)}$. LP has not been linked to the development of retinal vasculitis in the literature. Here, we present the case of a patient with LP with no additional disorder who developed bilateral retinal vasculitis, possibly due to LP.

\section{CASE REPORT}

A 44-year-old male patient presented to our clinic with symptoms of floaters in both eyes for a week. The best corrected visual acuity (BCVA) was 0.8 on the right eye and 0.9 on the left, and intraocular pressures were normal. The case had been followed up for mucosal LP for the last 10 years at another center. Anterior segment examination was normal for both eyes. Bilateral intensive vitritis and peripheral vascular sheathing were observed on fundus examination (Figure 1). FA investigation revealed staining and leakage of the mid-peripheral vessels in the early stage and of the optic disc and surrounding vessels in the late stage (Figure 2). The patient had no history of urogenital or oral ulceration, skin rash, weight loss, cough, night sweats, lymphadenopathy, arthritis, arthralgia, neurological symptoms, gastrointestinal symptoms, travel to foreign territories, or contact with animals. No evidence of pathology was found in tests performed to investigate the etiology of retinal vasculitis, and complete blood count, biochemical tests (glucose, urea, creatinine, electrolytes, and liver and kidney function tests), erythrocyte sedimentation, C-reactive protein, FTA-ABS, VDRL, Lyme IgM and IgG, HIV serology, urine analysis, rheumatoid factor (RF), anti-neutrophil antibody (ANA), tuberculin skin test (PPD), and chest $X$-ray tests were all normal. The results of cranial and orbital magnetic resonance imaging were normal. Consultations with various departments were performed to exclude Behcet's disease, sarcoidosis, systemic lupus erythematosus, multiple sclerosis, and tuberculosis, some of the most common etiologic causes of retinal vasculitis. Because of suspected $\mathrm{LP}$, fluocortolone tab (1 mg/kg), cyclosporine tab (2x $100 \mathrm{mg})$, and azathioprine tab (2 $\times 50 \mathrm{mg})$ were started as systemic treatment. No topical treatment was used. Corticosteroid treatment was gradually decreased and eventually stopped. BCVA fully recovered bilaterally at the first month of follow-up, and the vitritis and peripheral vascular sheathing had regressed. BCVA and anterior and posterior segment examinations were normal within the first year follow-up; therefore, the immunosuppressive treatment was discontinued (Figure 3).

\section{DISCUSSION}

LP is an autoimmune, inflammatory disease that affects the skin, skin appendages such as the hairs and nails, and the oral, vulvovaginal, esophageal, laryngeal, and conjunctival mucosa ${ }^{(1)}$. The res-
Submitted for publication: September 11,2015

Accepted for publication: January 7, 2016

Department of Ophthalmology, İnönü University Turgut Özal Medical Center, Malatya, Turkey.
Funding: No specific financial support was available for this study.

Disclosure of potential conflicts of interest: None of the authors have any potential conflict of interest to disclose.

Corresponding author: Seyhan Dikci. İnönü University Turgut Özal Medical Center. Department of Ophthalmology - Malatya, Turkey - E-mail: seyhandikci@gmail.com 


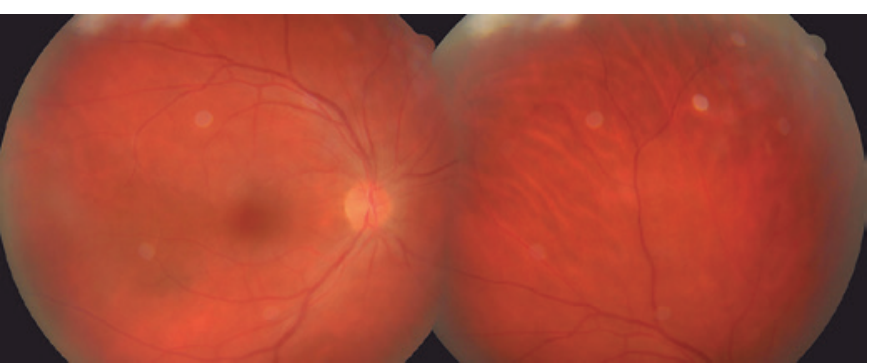

Figure 1. Color fundus photography showing mid-peripheral vascular sheathing. Images appear blurred because of intensive vitritis.

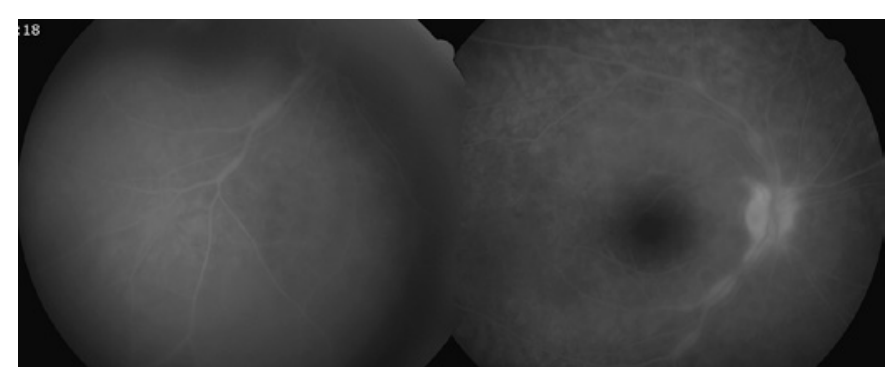

Figure 2. FA shows staining and leakage of the mid-peripheral vessels in the early stage and of the optic disc and surrounding vessels in the late stage.

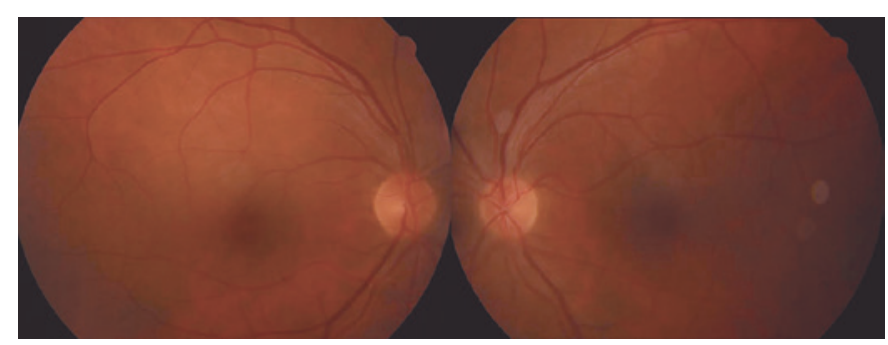

Figure 3. Post-treatment bilateral posterior segment examination was normal.

ponsible antigen for this T cell-dependent immunologic disease has not been identified ${ }^{(1)}$. Although the oral mucosa is generally affected by the type of LP that affects the mucosae, esophageal and ocular involvement may remain undetected. Serious eye problems related to the decrease in tear production may develop, and the patients have a relatively low number of conjunctival epithelial goblet cells $s^{(3)}$. Blepharitis, lacrimal duct obstruction, eyelid lesions, keratouveitis, keratoconjunctivitis sicca, punctate epithelial erosions, corneal ulcer/ scarring, and ocular surface squamous neoplasms such as dysplastic conjunctival lesions can also be seen in addition to xerophthalmia and cicatrizing conjunctivitis ${ }^{(1)}$. An isolated ocular form of LP has also been reported, and biopsy and immunofluorescence studies may be required to enable differentiation of this form from keratoconjunctivitis, which can also cause conjunctival scarring ${ }^{(1)}$.

Many inflammatory and infectious agents are included in the etiology of retinal vasculitis, and a proper diagnostic work-up should be performed in these patients ${ }^{(2,4-6)}$. However, in certain cases, no etiologic reason can be identified, a condition described as primary retinal vasculitis ${ }^{(4)}$. Some of these patients may later develop a systemic disease known to cause retinal vasculitis. Disorders that can cause retinal vasculitis fall into three groups, including systemic, infectious, and ocular disorders. Behcet's disease, sarcoidosis, multiple sclerosis, systemic lupus erythematosus, and Wegener's granulomatosis are the most common systemic diseases that can cause retinal vasculitis. The most common infectious diseases include toxoplasmosis, tuberculosis, Lyme disease, syphilis, cat scratch disease, and herpes simplex and varicella zoster infections, whereas ocular diseases include intermediate uveitis, Birdshot choroidopathy, and Eales disease ${ }^{(2,5,6)}$. CD4+T cell-dependent immunity is thought to play a main role in the pathogenesis of retinal vasculitis, but humoral immunity and immune complex formation may also be important ${ }^{(2)}$.

LP has not yet been reported in the literature as a cause of retinal vasculitis. Cellular immunity is known to play an important role in the pathogenesis of both retinal vasculitis and $L P^{(1,2)}$. In the present case, LP was suspected as the etiologic reason that the patient developed bilateral retinal vasculitis. To the best of our knowledge, this is the first case report on a patient developing retinal vasculitis due to LP.

\section{REFERENCES}

1. Gorouhi F, Davari P, Fazel N. Cutaneous and mucosal lichen planus: a comprehensive review of clinical subtypes, risk factors, diagnosis and prognosis. The Scientific World J. 2014;2014:742826.

2. Walton RC, Ashmore ED. Retinal vasculitis. Curr Opin Ophthalmol. 2003;14(6):413-9.

3. Şanlı B, Çetin EN, Bir F, Taşıı L, Yaldızkaya F, Yaylalı V. Conjunctival impression cytology, ocular surface and tear-film changes in patients with Lichen Planus. Clin Exper Dermatol. 2012;37(4):341-5.

4. George RK, Walton C, Whitcup SM, Nussenblatt RB. Primary retinal vasculitis. systemic associations and diagnostic evaluation. Ophthalmology. 1996;103(3):384-9.

5. El-Asrar AM, Herbort CP, Tabbara KF. A clinical approach to the diagnosis of retinal vasculitis. Int Ophthalmol. 2010;30(2):149-73.

6. El-Asrar AM, Herbort CP, Tabbara KF. Retinal vasculitis. Ocul Immunol Inflamm. 2005; 13(6):415-33 